\title{
A 5-year follow-up study of neonates with Hirschsprung's disease undergoing transanal Soave or Swenson surgery
}

This article was published in the following Dove Press journal:

Patient Preference and Adherence

\author{
Jianjun Zhang \\ Tongsheng $\mathrm{Ma}$ \\ Yuan Peng \\ Guangfeng Huang \\ Fengli Liu
}

Department of Neonatal Surgery,

Xuzhou Children's Hospital,

Xuzhou, China
Correspondence: Fengli Liu Xuzhou Children's Hospital, 18, North Sudi Road, Quanshan District, Xuzhou, 221000, Jiangsu Province, China

Tel +8651685583282

Fax +865168558308I

Email xzsetyywklf1@।63.com
Objective: To investigate different outcomes and long-term efficacy of transanal Soave or Swenson surgery in treatment for neonates with Hirschsprung's disease (HD).

Methods: In the present study, a total of 29 neonatal patients were included, with 20 patients undergoing the Soave procedure and nine patients undergoing the Swenson procedure. Data collected from the patients included basic demographics, age and weight at the time of operation, pathological typing, type of operation, operative time, blood loss, length of hospital stay, bowel function, and complications. The follow-up lasted for 5 years for all patients via the outpatient clinics or by telephone. Results were statistically analyzed using SPSS version 18.0.

Results: The age, weight, and pathological type of patients with different surgical approaches showed no significant difference. The operation time and blood loss of patients who underwent Swenson procedure were significantly lower than those who underwent Soave procedure; $P<0.05$. However, intraoperative complications showed no significant difference between the two groups; $P>0.05$. Bowel function (Rintala score) and postoperative complications in the two groups also showed no significant difference when evaluated 3 months after the surgery; $P>0.05$. Patients were followed-up for a 5-year period at 3 months, 6 months, 2 years, and 5 years after surgery, respectively. Results showed that complications and bowel function recovery during the 5-year follow-up showed no significant difference between the two methods.

Conclusion: The operation time and blood loss of the transanal Swenson pull-through procedure was lower than transanal Soave method; however the long-term outcomes of the two methods showed no significant difference. These results may give more clinical evidence in this field.

Keywords: Hirschsprung's disease, follow-up, transanal Soave, transanal Swenson, pull-through

\section{Introduction}

Hirschsprung's disease (HD) is a rare congenital disease affecting almost $2 \%$ of people worldwide, and is characterized by neonatal functional low bowel obstruction. ${ }^{1}$ HD leads to a serious developmental disorder of the alimentary system caused by an absence of ganglion cells in the distal region of intestinal wall. ${ }^{2}$ It varies in relation to age and extent of the disease. Generally HD usually affects newborns or babies in early infancy, however in the developing world, cases presenting late in childhood, adolescence or even in adults are still a challenge. ${ }^{3}$

With the development of surgical techniques and a deeper understanding of the pathological anatomy and physiology of the defect, more and more patients benefit from better prognosis and higher survival rate. The first operative approach for HD was reported by Swenson and Bill in 1948; ${ }^{4}$ since then, a lot of surgical strategies have been developed, such as the endorectal dissection ${ }^{5}$ and retrorectal procedure. ${ }^{6}$ 
In the last 3 decades, one of the most important developments for surgical management of HD has been the development of a single stage pull-through strategy which has gradually replaced the traditional 2 or 3 stage procedure. ${ }^{7}$

Among these strategies, the transanal Soave and Swenson methods are the latest methods adopted in clinical settings and are becoming increasingly popular. ${ }^{8,9}$ By performing an endorectal dissection and leaving a muscular cuff behind, it is considered that the Soave procedure can protect the surrounding structures and the area outside of the rectal wall from damage. ${ }^{10}$ The transanal Swenson pull-through operation is the earliest modification of the transanal approach that completely removes the aganglionic bowel. ${ }^{9}$ It is considered to be a combination of the transanal Soave method and transabdominal Swenson procedure. Compared to the traditional approaches, the transanal pull-through procedures have been shown to result in shorter hospital stay and fewer postoperative complications. ${ }^{11}$ However, there is still a group of patients who suffer from poor bowel emptying after the pull-through procedure ${ }^{12}$ and many studies have reported complications of these new procedures. ${ }^{1}$

Though there are several studies focusing on postoperative complications for HD patients undergoing transanal Soave and Swenson surgery, clinical data for the long-term prognosis of the two procedures for treatment of neonates are still inadequate. In this paper, we report a 5-year follow-up study for 29 HD neonates who received transanal Soave or Swenson surgery in our hospital. This study will give more clinical evidence for long-term effects of transanal Soave and Swenson procedures in treatment for neonates.

\section{Methods}

\section{Patients}

The present study is a retrospective analysis for 29 HD neonatal patients who received transanal Soave or Swenson surgery in Xuzhou Children's Hospital from April 2006 to December 2011. Among the patients, 20 patients (mean age $2.21 \pm 0.53$ years, male:female $=14: 6$ ) underwent the transanal Soave procedure and nine patients (mean age 2.59 \pm 0.44 , male:female $=7: 2$ ) underwent the Swenson procedure. All patients had symptoms of intractable constipation and abdominal distention, and needed to use glycerin enema to relieve the symptoms. Diagnosis was confirmed by barium enema and rectal mucosal biopsy. Patients who had laparoscopic or transabdominal operations were excluded from the study. Detailed clinical information of all patients is listed in Table 1. The present study was approved by the Ethics Committee of Xuzhou Children's Hospital. Written informed consent was obtained from all parents of the patients.
Table I Basic clinical information of the patients by procedure

\begin{tabular}{lllll}
\hline Characteristics & $\begin{array}{l}\text { Soave, } \\
\mathbf{n}=\mathbf{2 0}\end{array}$ & $\begin{array}{l}\text { Swenson, } \\
\mathbf{n}=\mathbf{9}\end{array}$ & $\begin{array}{l}\text { Total patients, } \\
\mathbf{n}=\mathbf{2 9}\end{array}$ & P-value* \\
\hline $\begin{array}{l}\text { Age at the time of } \\
\text { operation, years }\end{array}$ & $2.21 \pm 0.53$ & $2.59 \pm 0.44$ & $2.30 \pm 0.49$ & 0.832 \\
$\begin{array}{l}\text { Weight, kg } \\
\text { Pathological }\end{array}$ & $10.31 \pm 0.52$ & $10.69 \pm 0.63$ & $10.43 \pm 0.95$ & 0.651 \\
$\begin{array}{l}\text { typing } \\
\text { Short segment } \\
\text { (proximal and }\end{array}$ & 7 & 3 & & \\
middle rectum) \\
$\begin{array}{l}\text { Ordinary } \\
\text { (rectosigmoid) }\end{array}$ & 8 & 4 & & \\
$\begin{array}{l}\text { Long segment } \\
\text { (sigmoid and } \\
\text { descending) }\end{array}$ & 5 & 2 & & \\
\hline
\end{tabular}

Notes: *Comparison between Soave and Swenson. Data are presented as mean \pm $\mathrm{SD}$ or $\mathrm{n}$.

\section{Surgery}

Repeat cleansing enemas were given preoperatively for 5-20 days (median 7 days), and bowel preparation was performed 3 days before surgery, including improving the liquid diet, taking oral gentamicin, metronidazole and vitamin K4. The Soave procedure was conducted according to the technique described by De la Torre-Mondragon and Ortega-Salgado ${ }^{13}$ and the Swenson procedure was performed according to Sookpotarom and Vejchapipat's report. ${ }^{9}$ Although we did not perform a randomized controlled study, the principle of the surgical strategy, including the antibiotic regimen and surgical procedures, was the same in all patients.

\section{Data collection and follow-up}

Data collected from the patients included basic demographics, age and weight at the time of operation, pathological typing, type of operation, operative time, blood loss, length of hospital stay, bowel function, and complications. The Rintala scale was used to evaluate the bowel function recovery. ${ }^{14}$

The follow-up lasted for 5 years for all patients via outpatient clinics or by telephone. Information of postoperative complications and bowel function was recorded at 3 months, 6 months, 2 years, and 5 years postoperatively.

\section{Statistical analysis}

The measurement data are expressed by means \pm SD. Independent continuous variables were compared using the Student's $t$-test and categorical data were compared using the chi square test or Fisher's exact test. Data were considered to be statistically significant when $P$-value was less than 0.05 . All calculations were made using SPSS 18.0. 


\section{Results}

\section{Basic demographics of the patients}

In the present study, a total of 29 neonatal patients were included, with 20 patients undergoing the Soave procedure and 9 patients undergoing Swenson procedure. The age, weight and pathological typing results of patients with different surgical approaches showed no significant difference; $P>0.05$. We divided the patients into three groups; short segment HD (defined as those with aganglionosis extending to proximal and middle rectum), ordinary HD (defined as those with aganglionosis extending to rectosigmoid), and long segment HD (defined as those with aganglionosis extending to sigmoid and descending); for each surgical procedure. The basic clinical information of all patients is listed in Table 1 .

\section{Clinical outcomes of patients with different procedures}

Clinical outcomes of patients who underwent different procedures are listed in Table 2. The operation time, blood loss, length of hospital stay, bowel function, and complication data were collected and analyzed. Results showed that the operation time and blood loss of patients with Swenson

Table 2 Clinical outcomes of patients according to procedure

\begin{tabular}{|c|c|c|c|c|}
\hline Outcomes & $\begin{array}{l}\text { Soave, } \\
\mathrm{n}=20\end{array}$ & $\begin{array}{l}\text { Swenson, } \\
n=9\end{array}$ & $\begin{array}{l}\text { Total } \\
\text { patients, } \\
\mathrm{n}=29\end{array}$ & $P$-value* \\
\hline $\begin{array}{l}\text { Operation time, } \\
\text { min }\end{array}$ & $|93.35 \pm 26.5|$ & $|54.33 \pm 3| .26$ & $179.65 \pm 29.86$ & 0.031 \\
\hline Blood loss, mL & $49.33 \pm 11.12$ & $30.21 \pm 13.45$ & $40.22 \pm 12.54$ & 0.026 \\
\hline $\begin{array}{l}\text { Hospital stay, } \\
\text { days }\end{array}$ & $8.3 \pm 2.1$ & $7.2 \pm 2.3$ & $7.9 \pm 2.0$ & 0.863 \\
\hline Rintala score ${ }^{\#}$ & $15.12 \pm 3.14$ & $16.09 \pm 5.23$ & $15.69 \pm 4.97$ & 0.675 \\
\hline \multicolumn{5}{|c|}{ Intraoperative complications } \\
\hline Bowel injury & i & I & & \\
\hline Urethral injury & I & 1 & & \\
\hline Aganglionic & I & 0 & & \\
\hline bowel left & & & & \\
\hline behind & & & & \\
\hline Vaginal injury & I & 0 & & \\
\hline Total & $4(20 \%)$ & $2(22.2 \%)$ & & 0.728 \\
\hline \multicolumn{5}{|c|}{ Postoperative complications" } \\
\hline Fecal soiling & I & I & & \\
\hline $\begin{array}{l}\text { Anastomotic } \\
\text { fistula }\end{array}$ & I & I & & \\
\hline Enterocolitis & I & I & & \\
\hline $\begin{array}{l}\text { Recurrence of } \\
\text { constipation }\end{array}$ & i & 0 & & \\
\hline $\begin{array}{l}\text { Anastomotic } \\
\text { stenosis }\end{array}$ & I & 0 & & \\
\hline $\begin{array}{l}\text { Total colonic } \\
\text { prolapse }\end{array}$ & I & 0 & & \\
\hline Total & $6(30 \%)$ & $3(33.3 \%)$ & & 0.650 \\
\hline
\end{tabular}

Notes: *Comparison between Soave and Swenson. "Evaluated 3 months after surgery. Continuous data are presented as mean \pm SD and the other data are presented as $n$ or $\mathrm{n}(\%)$. procedure were significantly lower than those who underwent Soave procedure; $P<0.05$. However, intraoperative complications showed no significant difference between the two groups; $P>0.05$. Bowel function (Rintala score) and postoperative complications in the two groups also showed no significant difference when evaluated 3 months after the surgery; $P>0.05$.

\section{Complications and bowel function of the patients during 5-year follow-up}

All patients were followed-up for a period of 5 years: at 3 months, 6 months, 2 years, and 5 years after surgery. Results are shown in Table 3. For all patients, the complication rate gradually decreased. Six months after the surgery, one case experienced reoccurring symptoms of bellyache and constipation, two cases had fecal soiling, and one case had enterocolitis in the Soave group. Only two cases had enterocolitis and fecal soiling in the Swenson group, respectively. After 2 years, two cases had symptoms of constipation in the Soave group and one case had constipation in the Swenson group. After 5 years, only one case had symptoms of constipation in the Soave group. Rintala score was also recorded via outpatient review or telephone; results showed that the bowel function recovered steadily for both the groups. These results indicated that the longer term effect of the two surgical procedures did not show any difference.

\section{Discussion}

Inappropriate treatment of HD may lead to a life-threatening risk of enterocolitis in neonates or failure to thrive with defecation problems in older children. ${ }^{15}$ However, in recent decades, the treatment development has significantly enhanced its efficacy for HD patients. Both transanal Soave and Swenson approaches are the newest surgical techniques with a single stage pull-through strategy. Some studies suggested that HD patients who underwent single stage pull-through surgery had better prognosis than those who underwent multi-stage pull-through surgery. Sulkowski et al

Table 3 Complications and bowel function of the patients during 5-year follow-up period by procedure

\begin{tabular}{|c|c|c|c|c|}
\hline Indexes & 3 months & 6 months & 2 years & 5 years \\
\hline \multicolumn{5}{|c|}{ Complication, cases } \\
\hline Soave, $n=20$ & $6(30 \%)$ & $4(20 \%)$ & $2(10 \%)$ & I (5\%) \\
\hline Swenson, $n=9$ & $3(33.3 \%)$ & $2(22.2 \%)$ & I (II.I\%) & $0(0 \%)$ \\
\hline \multicolumn{5}{|l|}{ Rintala score } \\
\hline Soave, $n=20$ & $15.12 \pm 3.14$ & $15.76 \pm 3.26$ & $15.72 \pm 4.19$ & $15.30 \pm 5.02$ \\
\hline Swenson, $n=9$ & $16.09 \pm 5.23$ & $16.43 \pm 4.33$ & $16.21 \pm 3.68$ & $16.08 \pm 4.23$ \\
\hline
\end{tabular}

Note: Data are presented as $n$ (\%) for complications and as mean \pm SD for Rintala score. 
reported that most (77.2\%) of HD patients underwent single stage pull-through surgery and had lower rates of readmissions and additional operations. ${ }^{16}$ However, some studies showed different results; Sharma and Gupta reported that $82 \%$ of children with HD presenting late, required staged procedures due to dilated bowel. Single stage pull-through was feasible only in $18 \%$ of cases. ${ }^{17}$

Studies also showed that there were many complications after transanal Soave and Swenson surgeries. ${ }^{1}$ Though several studies have focused on the efficacy and safety of transanal Soave and Swenson surgeries, clinical data for long-term efficacy of the two surgical methods are still inadequate. In the present study, we demonstrated a 5-year follow-up study for neonates with HD undergoing transanal Soave or Swenson surgery.

Results showed that patients who underwent Swenson surgery had shorter operation time and less blood loss compared with the Soave method. However, complications and bowel function recovery during the 5-year follow-up showed no significant difference between the two methods. These results indicate that both transanal Soave and Swenson surgeries had good long-term efficacy for HD patients. Additionally, in terms of complications, we observed that none of the patients had fecal soiling or incontinence at 2 years and 5 years. We think this is because the patients were too young, making it difficult to determine incontinence for the families; and also the number of cases might have influenced the results.

Some related studies have reported similar results. Tang et al reported transanal Soave pull-through procedure for intestinal neuronal dysplasia in 17 children and results showed that the method was effective and safe. ${ }^{18}$ Yang et al demonstrated that transanal endorectal pull-through was a safe and effective procedure for HD which could reduce incidence of anastomotic stricture and constipation without increased soiling incidence. ${ }^{19}$ Recently, Bing et al reported a comparison of transanal pull-through Soave and Swenson techniques mainly for clinical outcomes, which showed that the Swenson method had shorter operation time, less blood loss, and lower complication rate. ${ }^{20}$ However, in an earlier study, Nasr et al reported that there were no significant differences in the short and intermediate term outcomes between transanal Soave and transanal Swenson pull-through procedures. ${ }^{21}$ In the present study, we observed that the operation time and blood loss of the transanal Swenson pull-through procedure was lower, however the long-term efficacy of the two methods showed no significant difference. These different results might be due to different patients and populations, which needs more clinical evidence to confirm.
The present study also has several limitations. First, this study was retrospective research, which means although the same surgical principle was used, differences do exist in patient treatments. Second, the number of cases in the present study is small, which may influence the result of the study.

In conclusion, we conducted a comparative study to investigate differences between transanal Soave or Swenson techniques in HD patients. Results showed that the operation time and blood loss of the transanal Swenson pull-through procedure was lower, however, the long-term efficacy of the two methods showed no significant difference. These results may give more clinical evidence in this field.

\section{Disclosure}

The authors report no conflicts of interest in this work.

\section{References}

1. Rintala RJ, Pakarinen MP. Long-term outcomes of Hirschsprung's disease. Semin Pediatr Surg. 2012;21(4):336-343.

2. Chhabra S, Kenny SE. Hirschsprung's disease. Surgery. 2016;34(12): 628-632.

3. Jarvi K LE, Koivusalo A, Rintala RJ, Pakarinen MP. Bowel function and gastrointestinal quality of life among adults operated for hirschsprung disease during childhood: a population-based study. Ann Surg. 2010;252(6):977-981.

4. Swenson O, Bill AH Jr. Resection of rectum and rectosigmoid with preservation of the sphincter for benign spastic lesions producing megacolon; an experimental study. Surgery. 1948;24(2):212-220.

5. Soave F. A new surgical technique for treatment of Hirschsprung's disease. Surgery. 1964;56:1007-1014.

6. Duhamel B. A new operation for the treatment of Hirschsprung's disease. Arch Dis Child. 1960;35:38-39.

7. Sosnowska P, Blaszczynski M. A 15-year experience with the one-stage surgery for treatment of Hirschsprung's disease in newborns, infants, and young children. Indian J Surg. 2015;77(Suppl 3):1109-1114.

8. Levitt MA, Hamrick MC, Eradi B, Bischoff A, Hall J, Pena A. Transanal, full-thickness, Swenson-like approach for Hirschsprung disease. J Pediatr Surg. 2013;48(11):2289-2295.

9. Sookpotarom P, Vejchapipat P. Primary transanal Swenson pullthrough operation for Hirschsprung's disease. Pediatr Surg Int. 2009; 25(9):767-773.

10. Dickie BH, Webb KM, Eradi B, Levitt MA. The problematic Soave cuff in Hirschsprung disease: manifestations and treatment. $J$ Pediatr Surg. 2014;49(1):77-80.

11. Romero P, Kroiss M, Chmelnik M, Konigs I, Wessel LM, HollandCunz S. Outcome of transanal endorectal vs. transabdominal pullthrough in patients with Hirschsprung's disease. Langenbecks Arch Surg. 2011;396(7):1027-1033.

12. Levitt MA, Dickie B, Peña A. Evaluation and treatment of the patient with Hirschsprung disease who is not doing well after a pull-through procedure. Semin Pediatr Surg. 2010;19(2):146-153.

13. De la Torre-Mondragón L, Ortega-Salgado JA. Transanal endorectal pull-through for Hirschsprung's disease. J Pediatr Surg. 1998;33(8): 1283-1286.

14. Rintala RJ, Lindahl HG, Rasanen M. Do children with repaired low anorectal malformations have normal bowel function? J Pediatr Surg. 1997;32(6):823-826.

15. Moore SW. Total colonic aganglionosis and Hirschsprung's disease: a review. Pediatr Surg Int. 2015;31(1):1-9.

16. Sulkowski JP, Cooper JN, Congeni A, et al. Single-stage versus multistage pull-through for Hirschsprung's disease: practice trends and outcomes in infants. J Pediatr Surg. 2014;49(11):1619-1625. 
17. Sharma S, Gupta DK. Hirschsprung's disease presenting beyond infancy: surgical options and postoperative outcome. Pediatr Surg Int. 2012;28(1):5-8.

18. Tang ST, Yang Y, Wang GB, et al. Laparoscopic extensive colectomy with transanal Soave pull-through for intestinal neuronal dysplasia in 17 children. World J Pediatr. 2010;6(1):50-54.

19. Yang L, Tang ST, Cao GQ, et al. Transanal endorectal pull-through for Hirschsprung's disease using long cuff dissection and short V-shaped partially resected cuff anastomosis: early and late outcomes. Pediatr Surg Int. 2012;28(5):515-521.
20. Bing X, Sun C, Wang Z, Su Y, Sun H, Wang L, Yu X. Transanal pullthrough Soave and Swenson techniques for pediatric patients with Hirschsprung disease. Medicine (Baltimore). 2017;96(10):e6209.

21. Nasr A, Haricharan RN, Gamarnik J, Langer JC. Transanal pullthrough for Hirschsprung disease: matched case-control comparison of Soave and Swenson techniques. J Pediatr Surg. 2014;49(5):774-776.

\section{Publish your work in this journal}

Patient Preference and Adherence is an international, peer-reviewed, open access journal that focuses on the growing importance of patient preference and adherence throughout the therapeutic continuum. Patient satisfaction, acceptability, quality of life, compliance, persistence and their role in developing new therapeutic modalities and compounds to optimize clinical outcomes for existing disease states are major areas of interest for the journal. This journal has been accepted for indexing on PubMed Central. The manuscript management system is completely online and includes a very quick and fair peer-review system, which is all easy to use. Visit http://www. dovepress.com/testimonials.php to read real quotes from published authors.

Submit your manuscript here: http://www.dovepress.com/patient-preference-and-adherence-journal 